Research Paper

\title{
TAF1L promotes development of oral squamous cell carcinoma via decreasing autophagy-dependent apoptosis
}

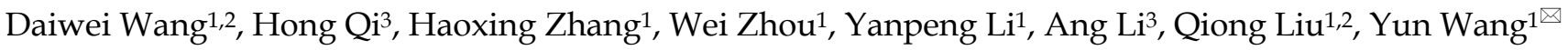 \\ 1. Center for Research and Technology of Precision Medicine, College of Life Sciences and Oceanography, Shenzhen University, Shenzhen, Guangdong, \\ China. \\ 2. Key Laboratory of Optoelectronic Devices and Systems of Ministry of Education and Guangdong Province, College of Optoelectronic Engineering, \\ Shenzhen University, Shenzhen, Guangdong, China. \\ 3. Key Laboratory of Shaanxi Province for Craniofacial Precision Medicine Research, College of Stomatology, Xi'an Jiaotong University. Xi' an, Shanxi, China \\ $\square$ Corresponding author: Center for Research and Technology of Precision Medicine, College of Life Sciences and Oceanography, Shenzhen University (Lihu \\ Campus), No. 1066, Xueyuan Ave, Nanshan Distract, Shenzhen, Guangdong (518055), P.R.China. Email address: yunw@szu.edu.cn.
}

(๑) The author(s). This is an open access article distributed under the terms of the Creative Commons Attribution License (https://creativecommons.org/licenses/by/4.0/). See http://ivyspring.com/terms for full terms and conditions.

Received: 2019.10.14; Accepted: 2019.12.26; Published: 2020.02.10

\begin{abstract}
This study focused on investigating the relationships of TAFIL expression and clinical features or pathological stages of oral squamous cell carcinoma (OSCC), and its potential roles of TAFIL on OSCC development. Western blot and immunohistochemical staining were used to detect TAFIL expression in OSCC tissues and cells. Effects of TAFIL on OSCC cells in vitro were examined by cell proliferation assay, wound healing assay, transwell chamber assay, flow cytometry analysis and siRNA technique. Cellular key proteins related to cell autophagy and apoptosis were evaluated by Western blot and immunofluorescent staining. Moreover, functions of TAFIL on OSCC process were observed in nude mouse model. Testing results showed that expression of TAF1L protein was higher in OSCC tissues than that in normal oral epithelial or paracancerous tissues. Additionally, the level of TAF1L protein expression was upregulated in OSCC cell lines, compared to that in normal oral epithelial cells. Furthermore, cell proliferation, migration, autophagy and apoptosis were modulated post siRNA-TAFIL treatment in vitro. Especially, TAF1L knockdown-induced apoptotic activation on OSCC cells could be rescued by autophagic activator (Rapamycin). Moreover, that overexpression of TAFIL protein could promote the growth of OSCC cell xenografts was confirmed in nude mouse model. Taken together, it suggests that TAFIL may facilitate OSCC cells to escape cell apoptosis via autophagic activation for enhancing OSCC development.
\end{abstract}

Key words: TAF1L, OSCC, apoptosis, autophagy, siRNA

\section{Introduction}

Oral squamous cell carcinoma (OSCC) is the most common carcinoma in human head and neck, which occurs approximately $90 \%$ of malignant tumors in oral cavity [1-3]. Approximately 350,000 patients with OSCC are newly diagnosed each year, and two-thirds of those cases are detected in South East Asian [4,5]. Although growing strategies of new treatments and diagnosis were generated over past decades, 5-year survival rate of OSCC has been less than $50 \%$ due to the many missed diagnosis and misdiagnosis at the early and middle stages of the tumor development, and detailed mechanism of
OSCC remains unclear. Thus, to discover novel key biomarkers for early diagnosis, precision medicine, prognosis and intervention has been become a hotspot in OSCC researches.

TATA-box binding protein associated factors (TAFs) are required for transcription initiation with RNA polymerase II. TAF1 is a major member of the TAF family, and its function is as a scaffold for binding TATA-box binding protein and TAFs to TFIID [6-8]. TAF1 like (TAF1L) is a TAF1 homologue, and till now, it has been found that both of them have a similar function with histone acetyltransferase 
activity $[9,10]$. In cancer researches, although it has known that TAF1 can play important roles on cell proliferation and apoptosis [11], little is known in regards to that is pathophysiological functions of TAF1L. Our primary studies via bioinformatics, RNA-seq and multiple immunohistochemistry revealed that TAF1L gene with somatic mutations and overexpression, as an oncogene, could promote OSCC and esophageal cancer procession [12,13]. Subsequently, growing studies have reported that deletions, point mutations, abnormal expression and inactivation of TAF1L were involved in the tumorigenesis of several cancers, such as lung, oral, gastric, colorectal, and urothelial cancers [14-17]. However, more researches for the roles of TAF1L gene in tumorigenesis are still needed.

Cell apoptosis, one major cell death form, plays critical functions in the body development and disease process, especially involved in many cancers development process $[18,19]$. Abnormal phenotype of TAF1 associated with cell apoptosis in cancers has been pointed out [20]. In addition, the autophagy, another cell death form, also plays important roles in maintaining cellular homeostasis, nutrient stress, hypoxia stress, oxidative stress and mitochondrial damage [21,22]. Occasionally, autophagic activation has been found to have the opposite effects in cancer development, according to tissue type and genotype [21,23-25]. As known as the relationship between the autophagy and apoptosis is involved in some proteins, such as ATG3, ATG5, ATG7, Bcl-2, Beclin-1 and etc. [26-28]. Recent researches indicated that the knockdown of those key genes associated with cell autophagy (such as ATG5, ATG7 and Beclin-1) could prevent the apoptosis $[29,30]$. Several scientists have found that both cell autophagy and apoptosis were associated with the prognosis of OSCC [31-34].

In this study, based on the hypothesis that TAF1L abnormal expression may mediate a crosstalk of the apoptosis and autophagy during OSCC procession, we focused on investigating effects of TAF1L on tissues and cells of OSCC in vitro and in vivo, as well as on the autophagy and apoptosis of OSCC cell lines post siRNA-TAF1L and Rapamycin administration.

\section{Material and Methods}

\section{Tissue collection}

Two commercial tissue microarrays were purchased from Biomax (USA): one array (ID: OR208) included 60 sections of OSCC tissue and 9 sections of normal oral tissue (per tissue section for each case, total 69 cases), and another array (ID: OR601b) included 50 sections of OSCC tissue and 10 sections of normal oral tissue (same as one section per case, total 60 cases). In addition, 11 archived formalin fixed-paraffin embedded samples obtained from oral normal epithelial or paracancer tissues after acute injury repair or benign tumor resection were collected and served as normal controls. Total testing numbers were 110 cases of OSCC tissue and 30 cases of normal oral/paracancerous tissue were utilized as research objects in this study. Clinical parameters (e.g., gender, TNM classification, clinical stage, pathological grade, and etc.) of all cases individually accompanying with the two tissue microarrays were provided by the Biomax and listed in Table 1. Executive collection and treatment of the tissue samples in this study were approved by the Medical Ethics Committee of Shenzhen University.

\section{Immunohistochemical staining (IHC)}

The tissue sections for IHC staining were firstly deparaffinized with xylene, and rehydrated with serial diluted alcohols. Sections with antigens were then retrieved in the egg-steamer with $10 \mathrm{mM}$ citrate buffer ( $\mathrm{pH} \mathrm{6.0)}$ at $100^{\circ} \mathrm{C}$ for $30 \mathrm{~min}$, and followed the incubation with $3 \% \mathrm{H}_{2} \mathrm{O}_{2}$ for 30 min, washed with PBS, and incubated with appropriate concentrations of primary antibody against special antigen at $4^{\circ} \mathrm{C}$, overnight. After washing with PBS again, sections were incubated with secondary antibody (goat anti-rabbit IgG-HRP, Zymed Laboratories, USA) for $60 \mathrm{~min}$ at room temperature. Positive signals were showed up by using AEC kit (GBI, USA), and nuclear counterstaining was done with hematoxylin. PBS replaced with primary antibody was served as negative staining. Anti-Ki67 antibody (Rabbit, 1:2000, Proteintech, USA), replacing the primary antibody, was selected as the positive control for checking the staining procedure. To set an immunopositive control, appointed tissue sections, which colorectal cancer tissue sections were selected in this study, were detected as corresponding to primary antibody against specific antigen. Immunoreactive scores (IRS) were assessed with positive percentage of total cells and positive intensity of mean obtained from 5 areas per section randomly under a microscope at $400 \times$ magnification $[35,36]$. Staining scores were achieved by two examiners independently, and showed a score consistently was $>82 \%$. If the image record was with different opinion from two examiners, the re-evaluation would be made by a third one. The degrees of positive signal intensity were determined using the following scale: 0 - none, 1 - weak, 2 moderate, 3 - intense and 4 - strongly intense. Percentages of positive cell were counted as (0) $0 \%$, (1) $1-25 \%$, (2) $26-50 \%$, (3) $51-75 \%$ and (4) $76-100 \%$. Final staining score was achieved by multiplying two 
scores of the degree of positive signal intensity and the percentage of positive cell. A score of $<2$ was considered as "negative" and $\geq 2$ as "positive", and the categories were used for statistical analysis.

\section{Antibodies and reagents}

Antibodies used in this study were obtained from (1) Proteintech (USA), including rabbit $\mathrm{pAb}$ against $\mathrm{TAF} 1 \mathrm{~L}$, rabbit $\mathrm{pAb}$ against $\mathrm{LC} 3 \mathrm{~B}$, rabbit $\mathrm{pAb}$ against Bax and rabbit pAb against P62/SQSTM1; (2) Cell Signaling Technology (USA), including rabbit $\mathrm{pAb}$ against $\mathrm{GAPDH}$, rabbit $\mathrm{pAb}$ against Caspase-3 and mouse mAb against Bcl-2; (3) Abmart (USA), mouse $\mathrm{mAb}$ against GFP; and (4) BD Biosciences (USA), secondary antibodies. The Alexa-conjugated secondary antibodies were from BD Biosciences (USA). In addition, the Rapamycin, an autophagic activator, was purchased from Solarbio (USA).

\section{Cell culture and transfection}

Four cell lines from oral tissues (HOEC, DOK, Tca-8113 and Ca9-22) were seeded at an initial density of $5 \times 10^{4} / \mathrm{cm}^{2}$ in collagen precoated 6 -well plates with RPMI-1640 medium or DMEM/Ham's F12 medium supplemented containing $10 \%$ fetal bovine serum, and incubated at $37^{\circ} \mathrm{C}$ with $5 \% \mathrm{CO}_{2}$. When growing up to approximately $70 \%$ confluence, cells were transfected with LC3-GFP plasmid (a kind gift from Dr. Jieli Wei, University of Chinese Academy of Sciences, China) and Lipofectamine 2000 (Invitrogen, USA). For siRNA transfection, cells were transfected using siRNA-TAF1L(s) and siRNA-negative control at $100 \mathrm{nM}$ concentration. Three reconstructed vectors of TAF1L gene silencing were generated with 3 pairs of sequencing primers (including sense and anti-sense primers), which were synthesized by Sangon Biotech (China), and listed as followed: TAF1L-siRNA\#1: 5'-GACCCAACAACCCUUCAUTT- ${ }^{\prime}$ and 5'-AUGA AGGGUUGUUUGGGUCTT-3'; TAF1L-siRNA\#2: $5^{\prime}$-GGAAGACUCUGAUGUGGAUTT-3' and $5^{\prime}$-AUC CACAUCAGAGUCUUCCTT-3'; TAF1L-siRNA\#3: $5^{\prime}$-GGAUGGGAAACCUAAGCCUTT- ${ }^{\prime}$ and $5^{\prime}$-AGG CUUAGGUUUCCCAUCCTT-3'; NC-siRNA: 5'-UCU CCGAACGUGUCACGUTT- $3^{\prime}$ and 5'-ACGUGACA CGUUCGGAGAATT-3'. After $48 \mathrm{hr}$ transfection, cells were treated for evaluating cell functions. To measure the efficacy of siRNA-TAF1L in transfected cells, expression levels of candidate protein were also analyzed by Western blot.

\section{Rapamycin treatment}

Each Ca9-22 or Tca8113 cell line was divided into two groups based on siRNA-TAF1L or siRNA-control treatment, and then each cell group was administrated with $0.1 \mu \mathrm{M}$ Rapamycin (Rapa) or same diluent (as negative control) for $16 \mathrm{hr}$. The cellular effects on candidate proteins of apoptosis and autophagy after Rapamycin administration were evaluated via Western blot.

\section{Generating stable TAFIL protein overexpression cells}

To establish stable TAF1L protein overexpression in OSCC cells, full length coding region of human TAF1L gene was subcloned into the pLV3-IRES-puro vector. And then, the TAF1L-pLV3-IRES-puro vectors were packaged into viral particles in HEK293T cells. When re-constructed Tca-8113 cells were selected as a stable TAF1L protein overexpression cell model, those cells were again treated with $0.5 \mu \mathrm{g} / \mathrm{ml}$ Neomycin for two weeks.

\section{CCK-8 cell proliferation assay}

Tca-8113 and Ca9-22 cells were seeded into 96-well culture plates with $3 \times 10^{3}$ cells per well. At each scheduled time point, a mixture of $100 \mu \mathrm{l}$ fresh medium and $10 \mu \mathrm{l}$ CCK- 8 (MCE, USA) was added per well, and plates with cells were incubated at $37^{\circ} \mathrm{C}$ for $1 \mathrm{hr}$. The absorbance of CCK-8 was detected at $450 \mathrm{~nm}$ using a microplate reader (BioTek, USA).

\section{Wound healing assays}

Tca-8113 cells and Ca9-22 cells were seeded in 12 -well culture plates at a density of $1 \times 10^{5}$ per well. When cells grew up to $~ 90 \%$ confluence, cell wound was created by scratching with a $200 \mu$ l-pipet tip. The cells were then washed with PBS, incubated with fresh media, and taken the photograph under a microscope, in order to observe scratching wound at 0 hr-start time point and at $48 \mathrm{hr}$-wound healing time point. The cell migration was assayed by measuring the distance between two edges of scratched wound at above pointed 0 and $48 \mathrm{hr}$ with Image-Pro Plus 6.0.

\section{Transwell chamber assay}

Cellular invasion capacity was examined using a 24 well Costar Transwell Chamber System with Matrigel matrix (BD Biosciences), according to the manufacturer's protocol. $2 \times 10^{4}$ cells per well were seeded into the upper chamber of this system with 0.5 $\mathrm{ml}$ of fresh medium containing 1\% FBS, and the lower chamber was filled with same volume of medium containing 15\% FBS, and then cells were incubated at $37^{\circ} \mathrm{C}$ in $5 \% \mathrm{CO}_{2}$ for $24 \mathrm{hr}$. After incubation, the filter membrane between the upper and lower chambers were fixed with the methanol, the cells remaining on the upper surface of the membrane were removed with a cotton swab, and the cells at lower surface of the membrane were stained with $0.5 \%$ crystal violet for $15 \mathrm{~min}$. The cells were finally recorded in 5 fields randomly under a microscope $(200 \times$ magnification), 
and numbers of invading cell were counted by Image-Pro Plus 6.0.

\section{Apoptosis detection with flow cytometry}

Tca-8113 and Ca9-22 cells were stained with FITC Annexin V Apoptosis Detection Kit II (BD), according to the manufacturer's protocol. After $48 \mathrm{hr}$ siRNA-TAF1L transfection, $1 \times 10^{6}$ cells $/ \mathrm{ml}$ of Tca8113 cells or Ca9-22 cells were washed with cold PBS, resuspended with binding buffer, incubated with $5 \mu \mathrm{l}$ Annexin-V-FITC reagent (positive signals can indicate early apoptosis) at room temperature for $5 \mathrm{~min}$, and stained with $10 \mu \mathrm{PI}$ reagent (positive signals can indicate late apoptosis) at room temperature for 5 min. The percentages of apoptotic cell were analyzed by FACS Calibur flow cytofluorometry (BD).

\section{Western blot}

Total cellular proteins were collected after different treatments and cultured in 6-well planes with RIPA lysis buffer (Biosharp, USA) containing protease cocktail (Roche, Germany) for $30 \mathrm{~min}$ at $4^{\circ} \mathrm{C}$. After the centrifugation at $14,000 \times \mathrm{g}$ for $10 \mathrm{~min}$ at $4^{\circ} \mathrm{C}$, each cellular lysate was transferred to a new $1.5 \mathrm{ml}$ centrifuge tube on ice, and protein concentration was determined with the BCA assay (Thermo Scientific, USA). For Western blot analysis, equal amounts $(20-30 \mu \mathrm{g})$ of cell protein were loaded on SDS polyacrylamide gels for electrophoresis, and transferred to nitrocellulose membranes (Whatman, Germany). The membranes were blocked with TBST contained 5\% BSA for $30 \mathrm{~min}$ at room temperature. Candidate proteins were identified with specific primary antibodies at $4^{\circ} \mathrm{C}$, overnight, and followed the incubation with horseradish peroxidase (HRP)-conjugated secondary antibody for $1 \mathrm{hr}$ at room temperature. The bands were visualized and measured via the ECL kit (Pierce, USA) and Tanon analysis system (Tanon, China).

\section{Immunofluorescent staining}

Tca-8113 cells and Ca9-22 cells were grown on precoated coverslips, and fixed in $2 \%$ PFA in phosphate-buffered saline (PBS) for $15 \mathrm{~min}$ at $37^{\circ} \mathrm{C}$. Cells were blocked with 3\% BSA in PBS for $30 \mathrm{~min}$ at room temperature for non-special staining, and cells were then incubated with primary anti-GFP antibody (1:500) and secondary antibody (Alexa Fluor 488, 1:500) for $1 \mathrm{hr}$ at room temperature orderly. For recording positive fluorescent signals of GFP puncta (green Color), an Olympus FV1000 microscope was used. The fluorescent images were taken with a $60 \times$ oil-immersion lens.

\section{Nude mice of OSCC}

Female nude mice ( 6 week-old, BALB/-nu) were divided into two groups randomly ( $\mathrm{n} \geqq 5$ for each group), and treated with the transfection of TAF1L-stable expression cells (Tca8113-TAF1L cells) or untreated control cells (Tca8113-control cells). The prepared cells were suspended in IMDM medium without serum, and a concentration at $6 \times 10^{6}$ cells was subcutaneously injected in one mouse back to establish xenogenetic model in vivo. The subcutaneous tumor growth was measured with a Vernier caliper every other day. The formula (length $\times$ width $^{2} / 2$ ) was served as for calculating tumoral volume. The animal tests for establishing nude mouse model were approved by the Experimental Animal Ethics Committee of Shenzhen-PKU- HKUST Medical Center.

\section{Statistical analysis}

All experimental data obtained from this study were performed with at least three biological repeats, except of the nude model. Error bars in the figures were represented Mean $\pm \mathrm{SD}$. Statistical analyses were performed by using SPSS 19.0, Graphpad prism 6 and Excel (Microsoft) with Student's $t$-test, one-way ANOVA, and Fisher's exact test. $p<0.01$ was considered as significant difference.

\section{Results}

\section{Overexpression of TAF IL was associated with OSCC process}

To observe the changes of TAF1L protein expression in OSCC procession in situ, IHC staining was performed on a total of 140 formalin fixed-paraffin embedded tissue cases, which included 110 cases of OSCC tissues and 30 cases of normal oral epithelial/paracancerous tissues. Positive TAF1L signals by IHC staining were showed that mainly distributed in the membrane and cytoplasm of cancerous epithelial cells and a few of infiltrating cells (Figure 1A). Comparatively, TAF1L signal intensity in OSCC tissue sections was much stronger than those in normal oral or paracancerous tissue sections (Figure 1A, B). Up to $87.3 \%$ (96 positive of total 110) expressed strong positive signals in OSCC tissues, on the contrary, only $28.1 \%$ had positive signals in normal oral or paracancerous tissues (9 positive of total 30 ). The difference between above two groups was statistically significant (Figure 1B; Tables 1 and 2; $p<$ 0.001). 
A

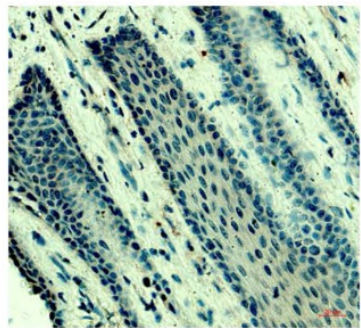

Para-cancer

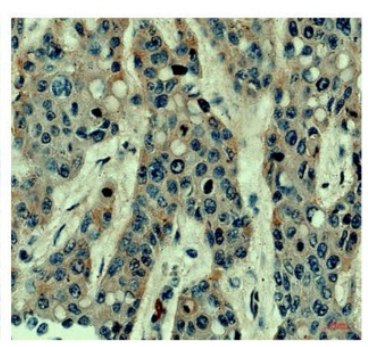

Cancer
B

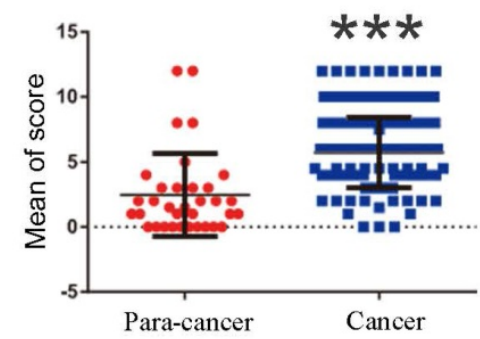

C
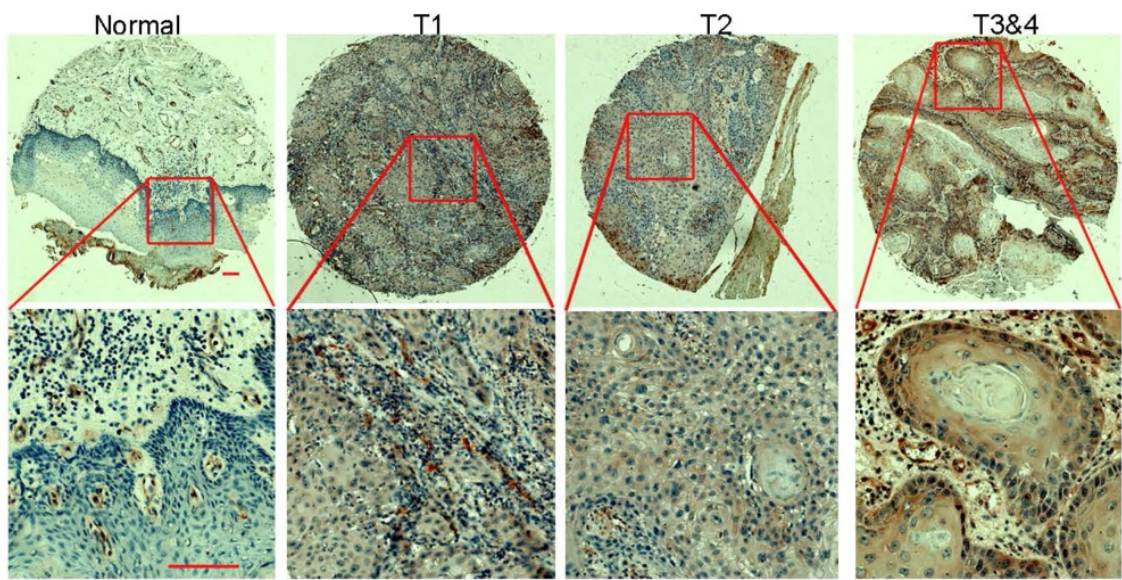

D

Figure 1. The levels of TAFIL protein expression in OSCC tissues and normal oral/paracancerous tissues were observed by IHC. A, TAF1L overexpression in OSCC tissues vs. TAFIL lower expression in normal tissues. Scale bars: $20 \mu \mathrm{m}$. B, Quantification of the mean scores of TAF1L positive signals between OSCC tissues and normal oral epithelial tissues. C, Overexpression of TAFIL in OSCC tissues was showed at different TNM-T stages, compared with normal oral epithelial tissues. Brown color showed positive signals. Scale bars: $20 \mu \mathrm{m}$ in the top row and $100 \mu \mathrm{m}$ in the bottom row. D, The means of density scores of TAF1L were showed higher at different TNM-T stages of OSCC, compared with normal oral epithelial tissues. OSCC tissues: $n=110$, normal oral/paracancerous tissues: $n=30$. Positive signals were showed with brown color. $* * * p<0.0001$ (one-way ANOVA).

Table 1. Clinical characteristics of OSCC patients obtained in this study

\begin{tabular}{lll}
\hline Parameters & Case numbers (n) & $\%$ \\
\hline Age (years) & & \\
$\leq 50$ & 37 & 61.82 \\
$>50$ & 73 & 39.18 \\
Gender & & \\
Female & 42 & 38.18 \\
Male & 68 & 61.82 \\
Histological differentiation & & \\
Well & 81 & 73.64 \\
Moderate & 15 & 13.64 \\
Poor & 21 & 19.09 \\
Clinical stage & & \\
I & 20 & 33.33 \\
II & 24 & 40 \\
III & 5 & 8.33 \\
IV & 1 & 1.67 \\
Unknown & 10 & 16.67 \\
T classification & & \\
T1 & 45 & 40.91 \\
T2 & 43 & 39.09 \\
T3 & 9 & 8.18 \\
T4 & 11 & 10 \\
Unknown & 2 & 1.82 \\
Anatomic site & & 61.82 \\
Tongue & 68 & 11.82 \\
Lip & 13 & \\
\hline
\end{tabular}

\begin{tabular}{lll}
\hline Parameters & Case numbers (n) & $\%$ \\
\hline Gingiva & 7 & 6.36 \\
Cheek & 5 & 4.55 \\
Maxillary sinus & 4 & 3.64 \\
Lower jaw & 4 & 3.64 \\
Upper jaw & 3 & 2.73 \\
Oral cavity & 3 & 2.73 \\
Palate & 1 & 0.91 \\
Parotid gland & 1 & 0.91 \\
Mandible & 1 & 0.91
\end{tabular}

Table 2. TAFIL protein expression in OSCC tissues or normal oral/paracancerous tissues by IHC

\begin{tabular}{lllll}
\hline & $\begin{array}{l}\text { Case } \\
\text { numbers } \\
\text { (n) }\end{array}$ & $\begin{array}{l}\text { Over-expression } \\
\text { (n) }\end{array}$ & $\begin{array}{l}\text { Over-expressive } \\
\text { ratio (\%) }\end{array}$ & $\begin{array}{l}p \text {-value } \\
\text { (Fisher's } \\
\text { exact test) }\end{array}$ \\
\hline Normal tissues & 30 & 9 & $28.1 \%$ & $\mathbf{0 . 0 0 3 3}^{*}$ \\
OSCC tissues & 110 & 96 & $87.3 \%$ & \\
\hline
\end{tabular}

* It means a statistically significant difference $(p<0.05)$.

Then, the relationships between TAF1L protein expression in OSCC tissues and clinical stage, differentiation grade or TNM stage of this disease were next investigated. Imaging results showed that the levels of TAF1L protein expression were significantly increased at all clinical and pathological 
phases of OSCC (Figure 1C, D; Table 3). Using the chi-square and Fisher's exact analyses, similar results were shown in the comparison of TAF1L protein expression at any two stages from differentiation grade I-II to III-IV and TNM T1-2 to T3-4. In addition, the association of the level of TAF1L protein expression with clinical or pathological feature of OSCC procession was also analyzed, and the results were listed in Table 3.

Table 3. The association between TAFIL protein overexpression and clinicopathological characteristics of OSCC patients

\begin{tabular}{|c|c|c|c|}
\hline \multirow{2}{*}{$\begin{array}{l}\text { Clinicopathological } \\
\text { characteristics }\end{array}$} & \multicolumn{3}{|c|}{ TAF1L expression } \\
\hline & Low (n) & High (n) & $p$-value \\
\hline \multicolumn{4}{|l|}{ Age (years) } \\
\hline$\leq 50$ & 13 & 44 & 0.6117 \\
\hline$>50$ & 10 & 43 & \\
\hline \multicolumn{4}{|l|}{ Gender } \\
\hline Female & 2 & 40 & 0.7079 \\
\hline Male & 6 & 62 & \\
\hline \multicolumn{4}{|l|}{$\begin{array}{l}\text { Histological } \\
\text { differentiation }\end{array}$} \\
\hline Well & 4 & 77 & 0.1654 \\
\hline Moderate, poor & 3 & 19 & \\
\hline \multicolumn{4}{|l|}{ Clinical stage } \\
\hline I & 8 & 4 & 0.2413 \\
\hline II-IV & 51 & 27 & \\
\hline \multicolumn{4}{|l|}{$\mathrm{T}$ classification } \\
\hline $\mathrm{T} 1$ & 3 & 42 & 1 \\
\hline T2-4 & 57 & 58 & \\
\hline
\end{tabular}

\section{Cell proliferation of OSCC was suppressed by TAFIL gene depletion}

As the expression of TAF1L protein was such higher in OSCC lesion (Figure 1), it seems to indicate that TAF1L may play important roles in cellular pathology of OSCC. Thus, the detection of TAF1L expression was performed in a panel of OSCC cell lines, such as Ca9-22 (cancerous gingival epithelia) and Tca-8113 (tongue cancer) cells, as appropriate cell lines for further testing. And they were compared with that expression in HOEC (normal oral epithelial cells) and DOK (dysplastic oral keratinocytes) by Western blot. From this test, the levels of TAF1L protein in both Ca9-22 and Tca-8113 OSCC cell lines were shown to have higher expression than that in normal cell line and DOK cell line (Figure 2A, B). Therefore, these two OSCC cell lines were chosen for transfecting siRNA-TAF1L and siRNA-control to assay the effects of TAF1L on OSCC cells in vitro. Then, cell proliferation in OSCC cell lines was examined with CCK-8 cell proliferation assay. Both growth rates of Ca9-22 and Tca-8113 cells were decreased after siRNA-TAF1L treatment at $72 \mathrm{hr}$ (both $p<0.001$; Student's $t$-test; Figure 2C-E). Those results showed that TAF1L gene silence could impede the growth of OSCC cells.

\section{The migration and invasion of OSCC cells were reduced after TAFIL gene depletion}

To investigate effects of TAF1L on cell migration and invasion of OSCC by siRNA technique, the results of wound healing and transwell assays were analyzed in TAF1L gene knockdown cells of Tca-8113 and Ca9-22. Migration distance was markedly decreased in siRNA-TAF1L group $(218.44 \pm 14.86 \mu \mathrm{m})$, compared with that in siRNA-control group (415.31 \pm $31.87 \mu \mathrm{m})(p=0.00088)$. The same trend of that change was also observed in Ca9-22 cells, in which migrated distance was $170.31 \pm 27.22 \mu \mathrm{m}$ in siRNA-TAF1L group and $498.50 \pm 29.01 \mu \mathrm{m}$ in siRNA-control group, $p=6.58511 \mathrm{E}-06$ (Figure 3A, B). Similarly, the numbers of invading cells were significantly suppressed in siRNA-TAF1L groups $(5.78 \pm 0.79 \%, 3.18 \pm 0.55 \%)$, compared with that in siRNA-control groups (13.04 \pm $2.22 \%, 9.91 \pm 1.29 \%)$ in both OSCC cell lines $(p<0.01$; Figure $3 \mathrm{C}, \mathrm{D})$. Those data showed that migratory and invasive abilities of OSCC cells could be inhibited via TAF1L gene silence.

\section{The upregulated apoptosis of OSCC cells was induced by TAFIL gene depletion}

In order to identify whether TAF1L expression can affect the apoptosis of OSCC cells, assays of flow cytometry and Western blot were performed to evaluate cell apoptosis in Tca-8113 cells and Ca9-22 cells post TAF1L gene depletion via siRNA-TAF1L. In results of flow cytometry, the ratios of apoptotic cells (including early apoptotic cells ratio + late apoptotic cells ratio) in both Tca-8113 and Ca9-22 cells were increased in siRNA-TAF1L treated groups (17.445 \pm $0.272 \%$ and $15.117 \pm 1.190 \%$ ), compared with that in siRNA-control groups $(12.555 \pm 0.257 \%$ and $11.710 \pm$ $0.184 \%),(p<0.001$; Figure 4A, B). Then, classical protein markers of apoptotic proteins (e.g., Caspase-3, Bcl-2, and Bax) were also evaluated by Western blot. As expected, the levels of key proapoptotic proteins (Caspase-3 and Bax) were upregulated, and Bax/Bcl-2 ratio was also increased in siRNA-TAF1L treated groups, compared with that in siRNA-control groups in both Tca-8113 and Ca9-22 cells $(p<0$. 01; Figure 4 C, D). Those results indicated that apoptosis of OSCC cells could be significantly induced by TAF1L gene depletion.

\section{The autophagy of OSCC was inhibited by TAFIL gene depletion}

In order to evaluate the effects of TAF1L gene on autophagy of OSCC cells by the gene knockdown, Western blot and Immunofluorescent staining assays were carried out in Tca-8113 and Ca9-22 cells. Firstly, the levels of key protein expression related autophagy (e.g., LC3B and p62) were detected by Western blot. 
Then the level of LC3B protein expression was downregulated and the level of p62 protein expression was upregulated in both Ca9-22 cells and Tca-8113 cells after siRNA-TAF1L treatment, compared with that in normal cells $(p<0.01$; Figure 5A, B). To confirm their effects, LC3-GFP plasmid was further transfected for analyzing autophagic effects on OSCC cells. As shown in Figure 5C, the numbers of LC3-GFP punctum decreased when OSCC cells were treated with siRNA-TAF1L, compared with that in control cells $(p<0.01$; Figure 5C, D). Above results demonstrated that depletion of TAF1L could inhibit cell autophagy of OSCC.

\section{The autophagy-depended apoptosis in TAFIL gene depleted-OSCC cells was verified by Rapamycin administration}

The relationship between the autophagy and apoptosis was clarified in TAF1L gene depleted-OSCC

\section{A}

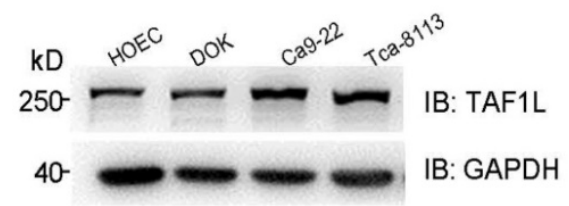

C

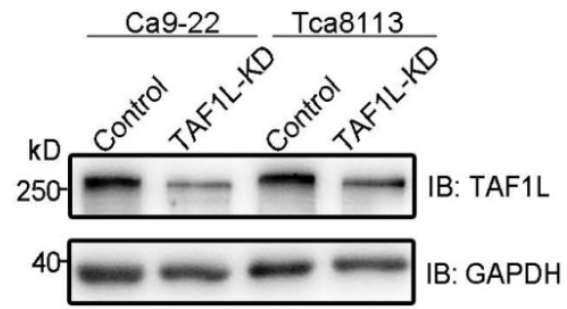

$\mathbf{E}$

Ca9-22

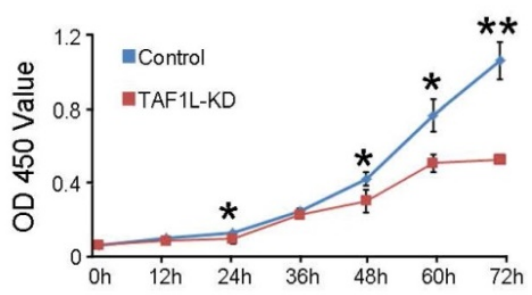

cells. Since early data from this study showed that TAF1L gene depletion might inhibit autophagy in OSCC cells, Rapamycin [37], a well-known autophagic activator, was used to reveal the effects of TAF1L on both Tca-8113 cells and Ca9-22 cells via that gene knockdown. By contrast, results from Western blot showed that the level of LC3B protein expression was increased, while the level of p62 protein expression was decreased after Rapamycin administration. Those data points seem to indicate that the autophagic activation of Tca-8113 and Ca9-22 cells could be resulted in Rapamycin treatment. In addition, after treating $0.1 \mu \mathrm{M}$ Rapamycin for $16-24$ $\mathrm{hr}$, the expression of Caspase- 3 was also reduced (Figure 6A, B). Intriguingly, ratios of apoptotic cell in both Tca-8113 and Ca9-22 cell lines were directly decreased by Rapamycin, when TAF1L gene expression was suppressed (Figure 6C, D). However, cells treated with Rapamycin alone was failed to affect

B

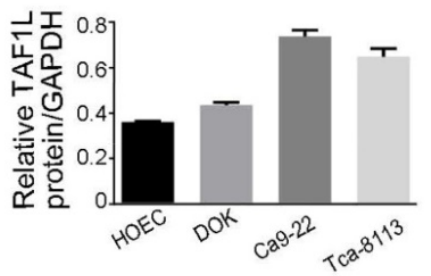

D

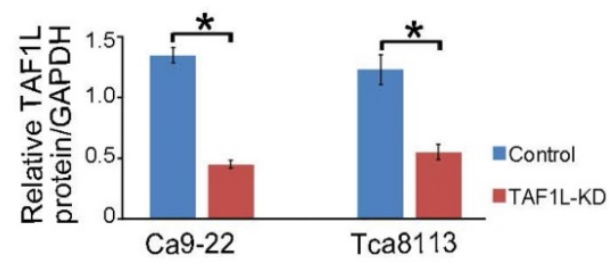

Tca8113

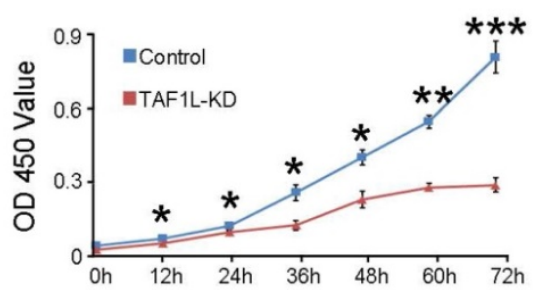

Figure 2. The levels of TAFIL protein expression of OSCC cells after TAFIL gene knockdown with siRNA technique were detected by Western blot and CCK-8 assays. A, TAFIL protein expression of a panel of OSCC cells was showed with special antibody against TAFIL antigen. B, TAFIL protein level related to (A) was measured based on the intensity of Western blot. C, Cells were detected after $48 \mathrm{hr}$ transfection with selected siRNA-TAFIL or siRNA-control. Verification of TAFIL gene knockdown post siRNA treatment in Ca9-22 cells or Tca-8113 cells was via Western blot with antibody against TAFIL or GAPDH. D. Downregulation of TAFIL was tested at the protein level related to (C). E, Using the CCK-8 assay and cell proliferation were measured in Tca-8113 cells and Ca9-22 cells after siRNA-TAFIL (TAFIL-KD) or siRNA-control transfection for time response. Cell viability was determined at scheduled time point. Data were showed Mean $\pm S D, N=3,{ }^{*} p<0.01,{ }^{* *} p<0.001$, ${ }^{* * * *} p<0.0001$ (Student's t-test). 
cell apoptosis in this system. So that with the feedback for autophagic activation might be as a driver for apoptotic decrease in TAF1L-depleted OSCC cells. Results in this study indicated that TAF1L gene overexpression could reduce the apoptosis through the inhibition of the autophagy in both Tca-8113 and Ca9-22 cells.

\section{TAFIL protein expression enhanced tumor growth in OSCC in vivo}

To evaluate the effects of TAF1L protein overexpression on tumor growth of OSCC in vivo, Tca-8113-TAF1L cells with the clone expressed TAF1L protein stably or Tca-8113-NC cells with the clone expressed negative control protein stably (as negative controls) were injected into the back of nude mice with subcutaneous route. The results showed that the xenograft volumes were obviously increased in the Tca-8113-TAF1L group, compared with that in the Tca-8113-NC group (Figure 7A, B). The tumor weight was also slightly enhanced in Tca-8113-TAF1L group, compared with that in Tca-8113-NC group (Figure 7C). The correlation among TAF1L gene, apoptosis and autophagy related markers in tumor lesions from mouse model was verified by using IHC. Images of
IHC staining demonstrated autophagic marker - LC3 was upregulated slightly, whereas apoptotic marker Caspase 3 was downregulated in tumor tissues post TAF1L - overexpression treatment in vivo (Figure 7D). These findings mean that overexpression of TAF1L could promote tumor growth of OSCC in vivo.

\section{Discussion}

A majority of OSCC cases are associated with high rate of incidence, recurrence, deterioration and death, and with the 5-year survival rate at lower level when they diagnosis at middle and late phases $[38,39]$. In order to find novel biomarkers for early diagnosis and precision treatment, many mutations in some genes, such as FAT1, TP53, CDKN2A, CASP8 and NOTCH1, were more frequently detected in OSCC patients by whole exome sequencing [40]. However, the relationship between their effects on pathological procession and clinical outcome of OSCC patients need to be clearly studied. Meanwhile, for understanding the molecular mechanism of OSCC is also significant to benefit effective intervention of OSCC development.

\section{$\mathbf{A}$}
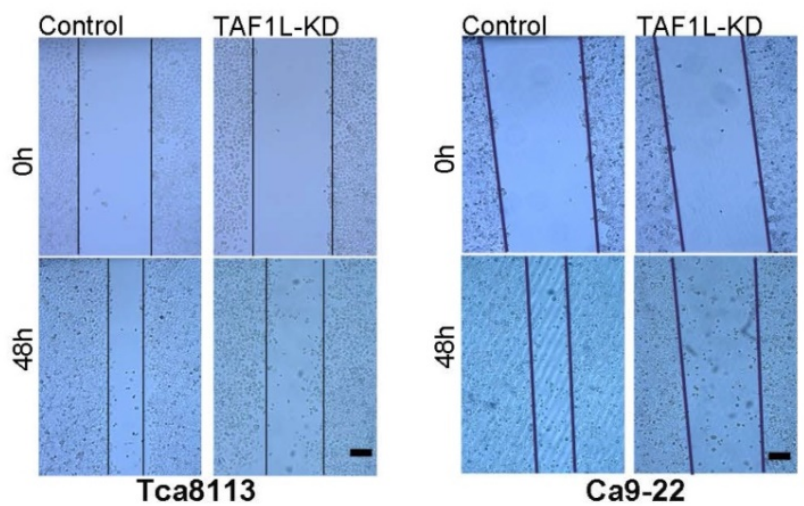

D

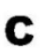

\section{B}

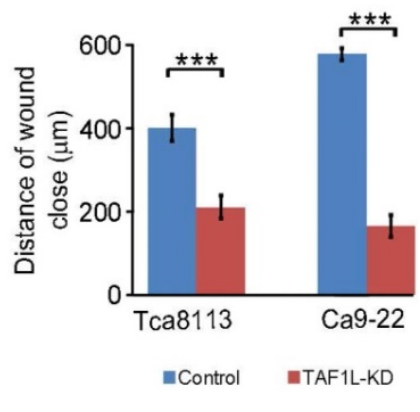

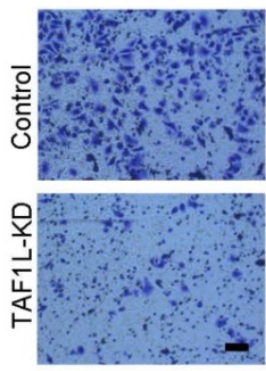

Tca8113
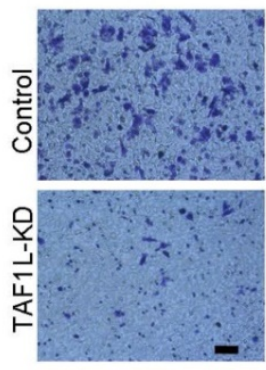

Ca9-22

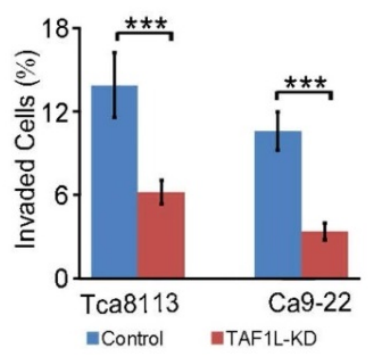

Figure 3. The migration and invasion of OSCC cells were decreased by siRNA-TAFIL treatment. A, Cell migration into the open space was monitored. Scale bars: $100 \mu \mathrm{m}$. B, Quantification of the length of migration was generated at appoint time after wounding was made from (A). C, Cell numbers for measuring the invasion were counted via transwell invasion assay. Scale bars: $100 \mu \mathrm{m}$. D, Those invading cells were counted, and compared with those obtained from (C) for quantified analysis. Scale bars: $100 \mu \mathrm{m}$, Student's $t$-test: Mean $\pm S D, N=3, * * p<0.001, * * * p 0.0001$. 

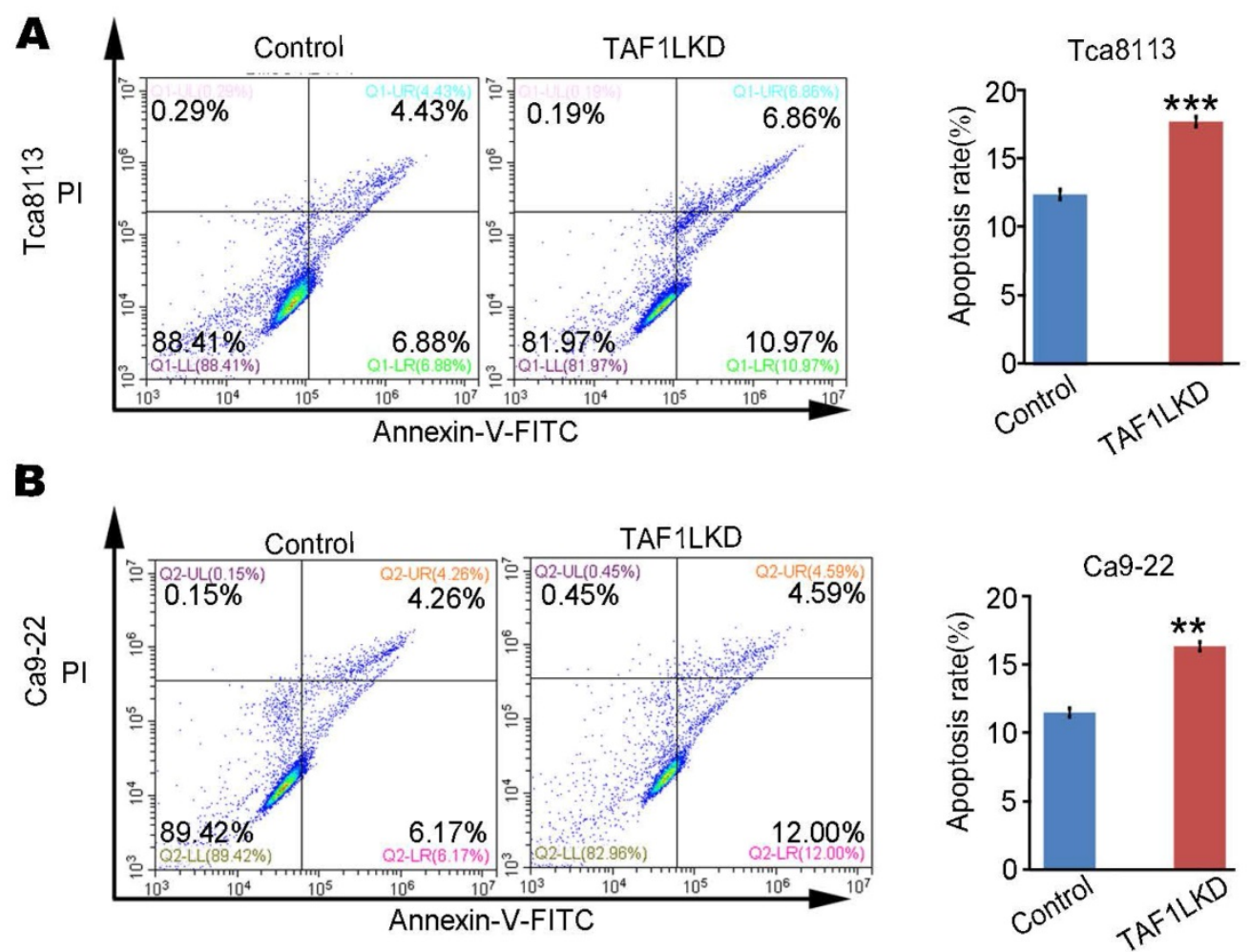

C

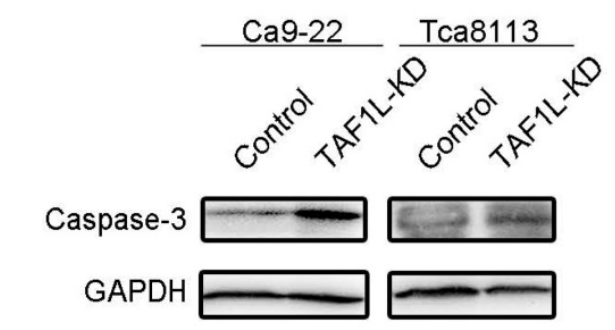

D
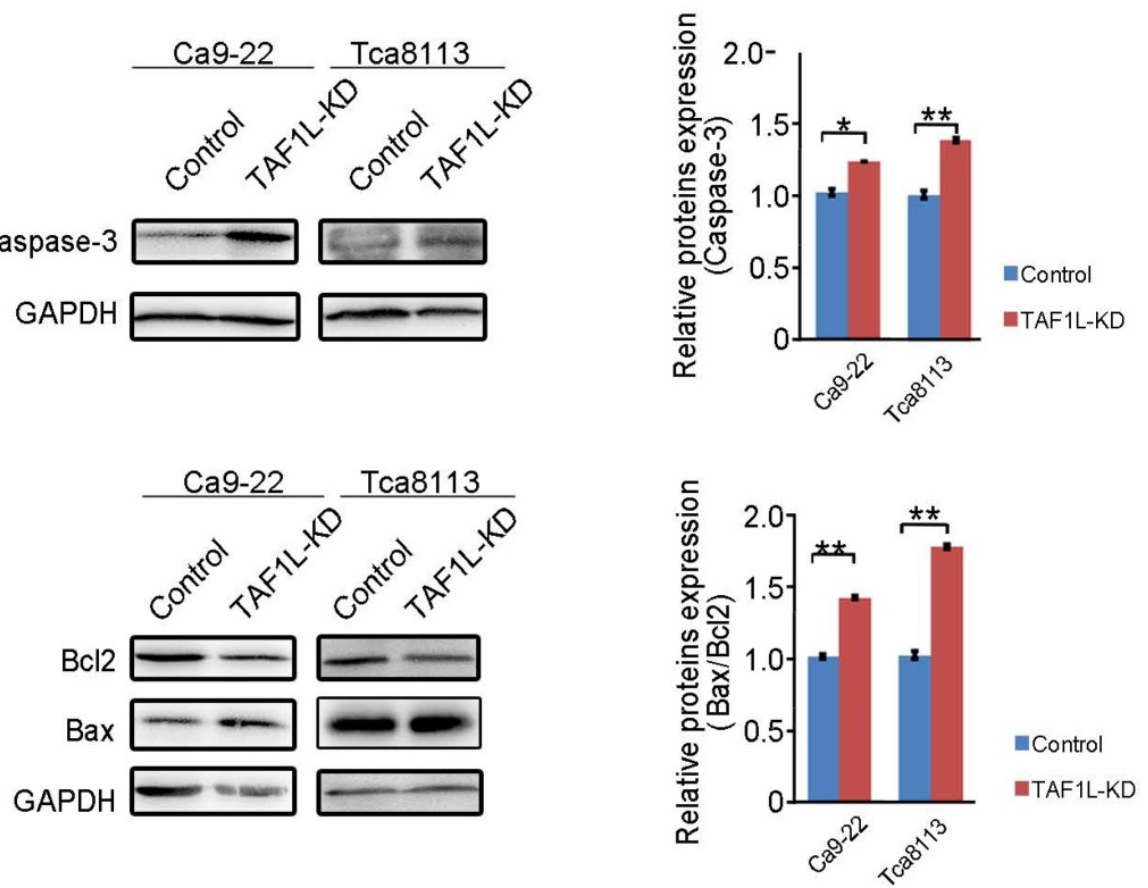

Figure 4. Apoptosis of OSCC cells were evaluated by TAFIL gene silence. A and B: The rates of cell apoptosis were observed in Tca-8113 cells (A) and Ca9-22 cells (B) transfected siRNA-TAFIL (TAFIL-KD) under a flow cytometer. C: Effects of TAFIL gene knockdown on cell apoptosis related Caspase-3 protein in Tca-8113 cells and Ca9-22 cells were detected with Western blot. D: Effects of TAFIL gene knockdown on apoptosis related Bax and Bcl-2 proteins in Tca-8113 and Ca9-22 cells were evaluated with Western blot. Protein quantification: Mean $\pm \mathrm{SD}, \mathrm{N}=3,{ }^{*} \mathrm{p}<0.01,{ }^{* * *} \mathrm{p}<0.001$ (Student's t-test).

Currently, there is little known regarding the biological functions of TAF1L, especially its pathological effects on cancer. Up until now, only a few research studies have reported that TAF1L mutation is associated with cancer pathogenesis. For example, a current study found that recurrent mutations of TAF1L gene were correlated with the pulmonary carcinoid tumor [14]. TAF1L frameshift mutations were found in gastric and colorectal cancers due to mononucleotide repeats [16]. Andrea et 
al. displayed that missense mutations in TAF1L gene were observed in advanced urothelial cancer [17]. However, its mechanism and effects on cancer development remain obscure. In previous study, we used RNA-seq in mutation screening, and identified TAF1L as both significantly mutated gene and tumor-specific disruptive gene in OSCC [13]. The same trend was found in the Japanese population, the numbers of somatic mutation of TAF1L in OSCC was approximately $10.6 \%$ [15]. This study intended to reveal relationships of TAF1L expression with clinical features or pathological stages of oral squamous cell carcinoma. Via the image results of IHC staining, TAF1L signal intensity in OSCC tissue sections was much stronger than those in normal oral/paracancerous tissue sections. Comparatively, $\geq$ $87.3 \%$ strong positive signals of TAF1L protein was in OSCC tissues and only $\leq 28.1 \%$ weak positive signals of that was in normal oral and paracancerous tissues. Additionally, TAF1L protein was abnormally overexpressed in OSCC lesions at all clinical and pathological phases, even if it was at very early phase, and it was also showed more overexpression at severity phase. Moreover, that TAF1L protein overexpression could promote the xenograft growth of OSCC was confirmed in nude mouse model. Taken together, this new finding suggested that the regulation of TAF1L protein expression can be as novel strategy for assisting early diagnosis and regulating OSCC process.

In this study, for investigating potential roles of TAF1L in OSCC via cell autophagy and apoptosis in vitro were at the next step. The levels of TAF1L protein expression were upregulated in two OSCC cell lines (Ca9-22 and Tca-8113), compared with that in normal oral epithelial cells (HOEC) and dysplastic oral keratinocytes (DOK) by Western blot. Furthermore, cell proliferation, migration, autophagy and apoptosis of both OSCC cell lines were modulated by siRNA-TAF1L treatment. Cell apoptosis and autophagy were obviously abnormalities in OSCC cells post TAF1L gene silence.

To avoid cell apoptosis is a typical characteristic in the most of cancers. Moreover, cell autophagy and apoptosis were pivotal regulation in the development of cancer, which could result in the severity of canceration $[41,42]$. Increasing numbers of research has demonstrated that chemotherapeutic and
A

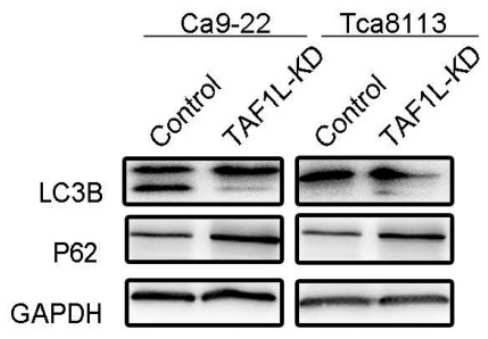

B

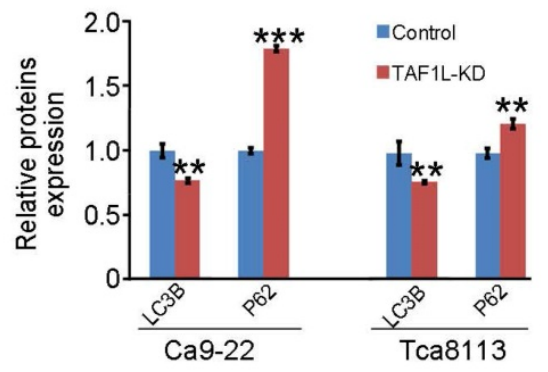

D

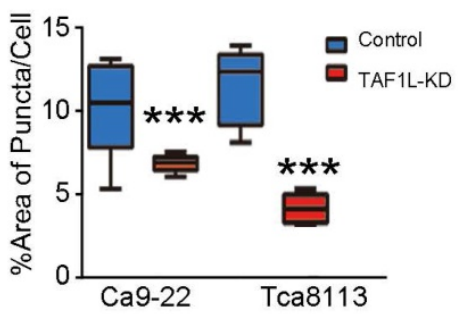

Figure 5. Effects of TAFIL gene depletion on cell autophagy were showed in OSCC cells. A, Autophagy-related proteins (LC3B and p62) were detected post TAFIL gene knockdown by Western blot. B, Proteins quantification was related to (A). C, Autophagic activity was assayed via confocal microscopy with immunolabeling for autophagy-related LC3B-GFP (green color). Scale bars: $5 \mu \mathrm{m}$. D, Quantification of the ratio of green dot area (LC3B-GFP) to total cell area in (C). $>30$ cells per condition from three independent experiments were analyzed. Mean $\pm S D, N=3,{ }^{*} p<0.01,{ }^{* * *} p<0.001,{ }^{* * * *} p<0.0001$ (Student's $t$-test). 
phytochemical agents induced cell apoptosis was through reducing autophagy in tumors [43-46]. As a potential protumor gene, TAF1L may have an important role as a regulator in response to the stresses for the apoptosis of cancer, which functions are similar to TAF1 gene (its homologous family member) [20]. Especially, it was rescued TAF1L gene knockdown-induced increase of apoptosis in OSCC cells, when autophagy activity is elevated. Taken together, the results showed that TAF1L could downregulate the apoptotic role for enhancing OSCC development via autophagic activation. The test indicates that inhibition of TAF1L protein expression may serve as potential therapeutic targets.
A
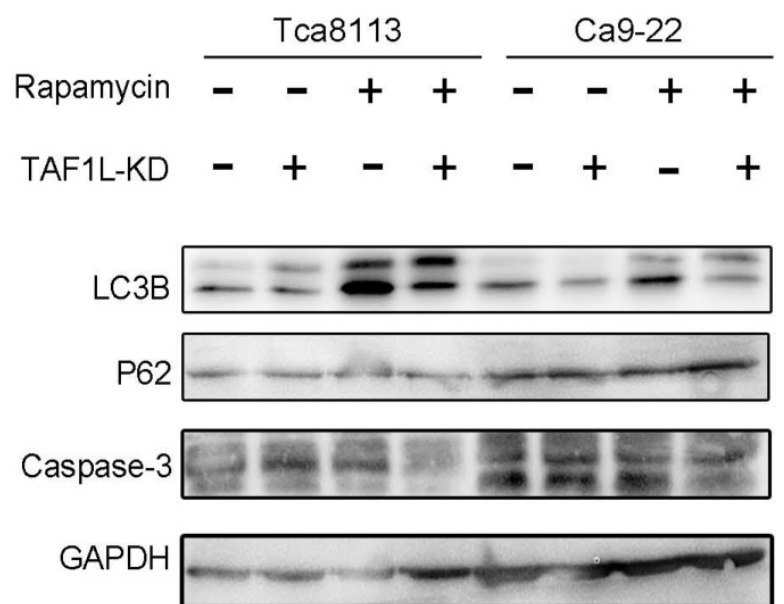

C

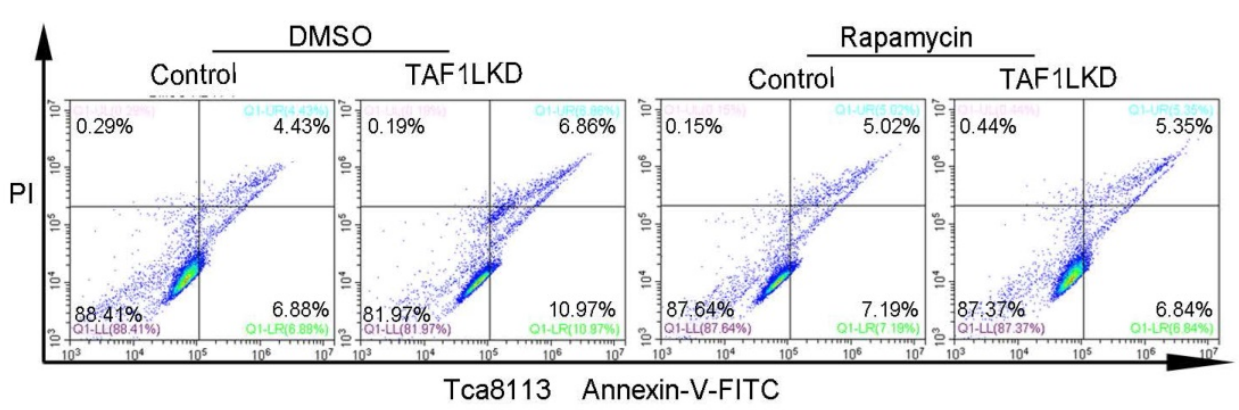

D

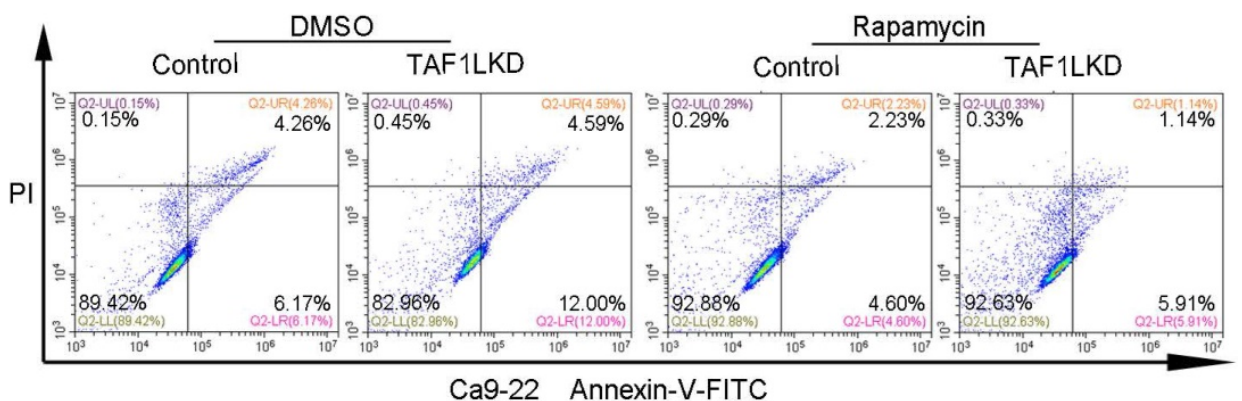

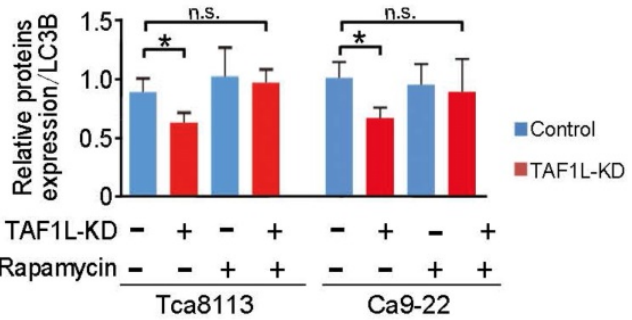

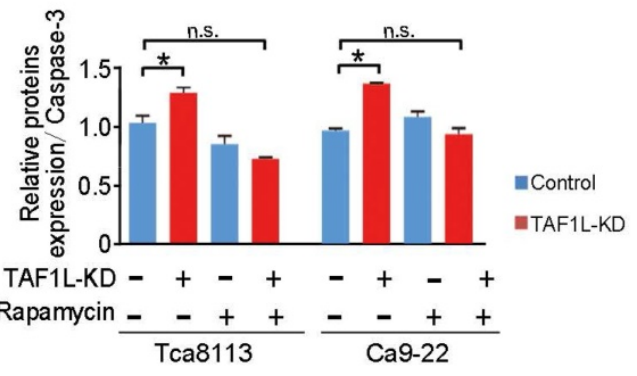

Tca8113

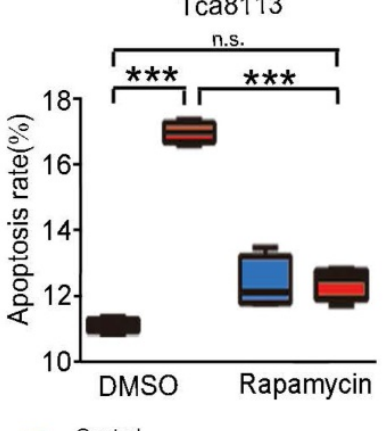

믄ol
TAF1L-KD

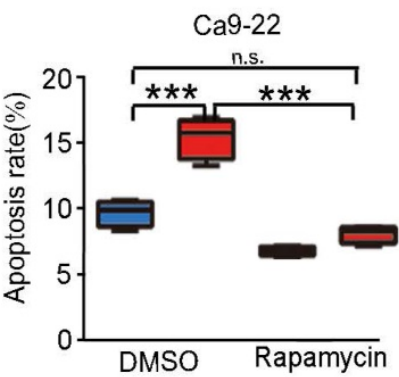

Figure 6. TAFIL gene silence-induced apoptosis in OSCC cells could be rescued by the Rapamycin treatment. The Ca9-22 and Tca8113 cells were divided into two groups based on siRNA-TAFIL or siRNA-control treatment, and then treated with $0.1 \mu \mathrm{M}$ Rapamycin (Rapa) or the diluent with same concentration of dimethyl sulphoxide (DMSO) for $16 \mathrm{hr}$. A, Autophagy- and apoptosis-related markers (e.g., LC3B, p62 and Caspase-3) were tested with Western blot. B, Levels of protein expression in (A) were shown up (Mean \pm SD, $N=3,{ }^{*} p<0.01$, one-way ANOVA). C-D, By flow cytometry, the image on the left showed changes of apoptotic cell ratios in Tca-8113 cells (C) and Ca9-22 cells (D), and on the right one showed percentages of apoptotic cell in the same cell line. Mean $\pm S D, N=3, * p<0.01$, $*^{*} p<0.001$, $* * * p<0.0001$ (Student's $t$-test). 
A

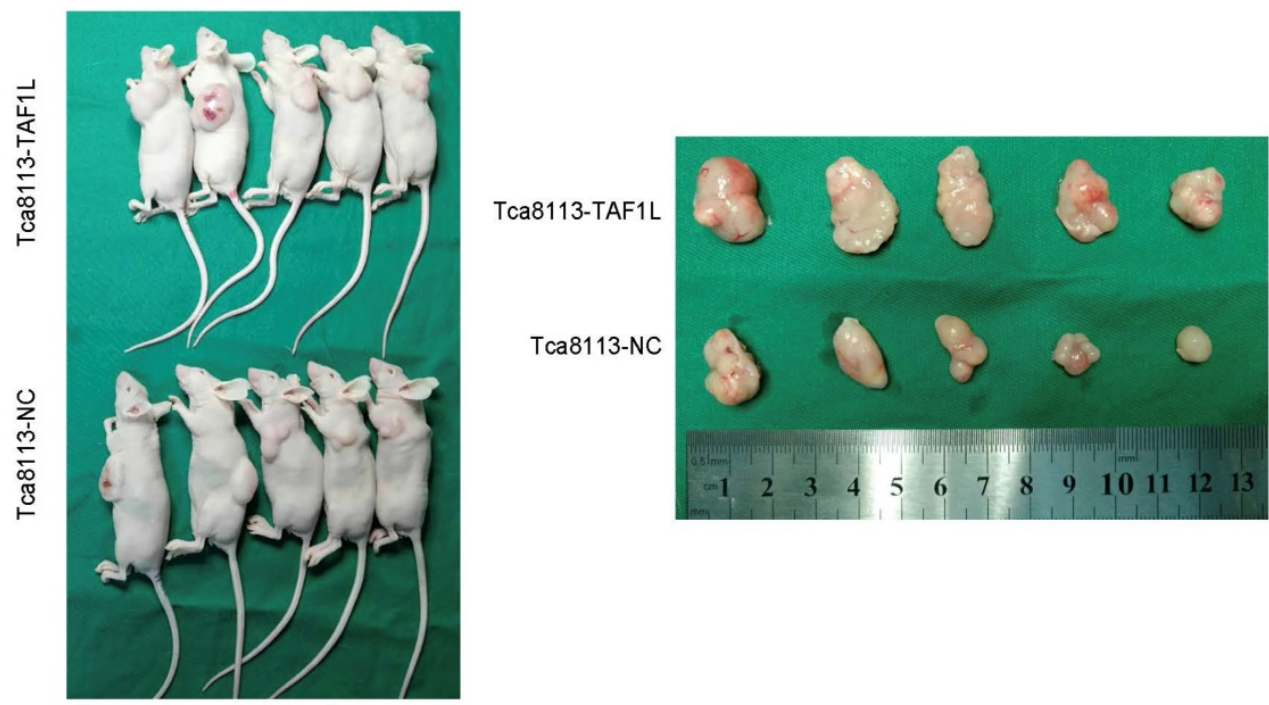

B

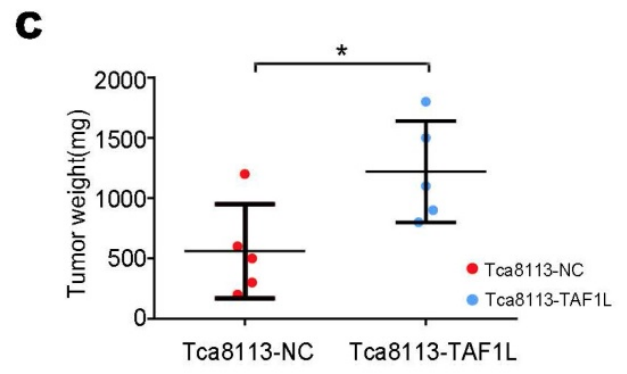

D
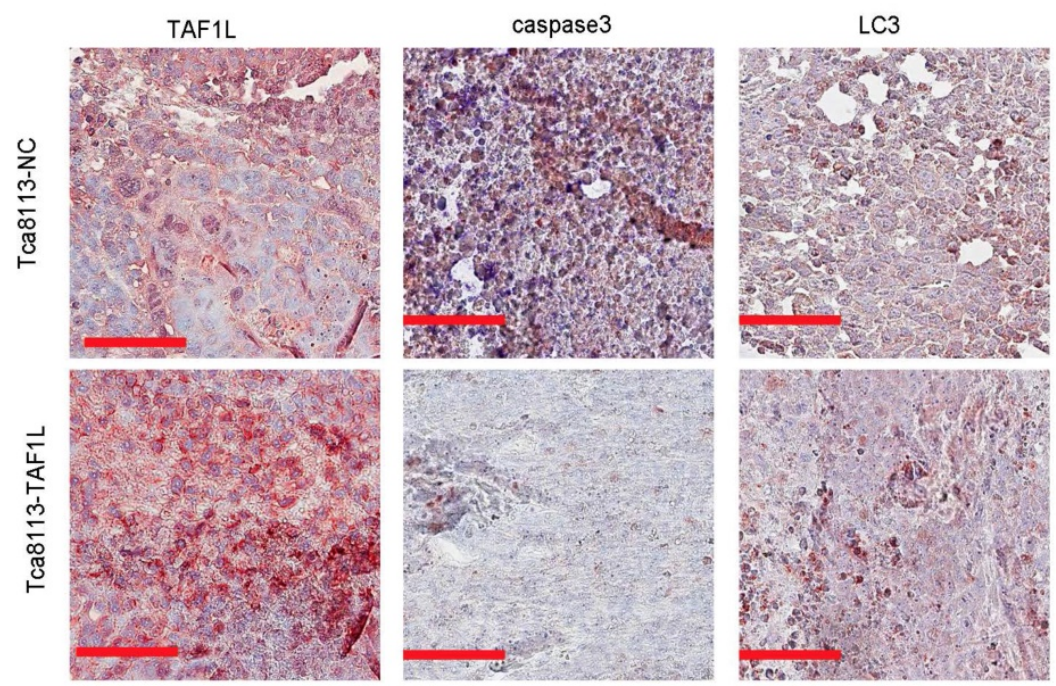

Figure 7. TAFIL overexpression promoted OSCC tumor growth in vivo. A, Female nude mice (left) and tumor xenograftes (right) were represented at 35 days post subcutaneous injection. B, The curves of tumor volume in nude mice were showed up (*** $p<0.001$. Student's $t$-test). C, The curves of tumor weight were represented at 35 days post subcutaneous injection, ${ }^{*} p<0.05$ (Student's $t$-test). D, Comparison of TAF1L, apoptosis and autophagy markers expressions in the xenograft model. Scale bars: $100 \mu$ m.

\section{Acknowledgments}

This study was supported by the Science and Technology Program, the Science and Technology Innovation Committee of Shenzhen, Grant No.
JCYJ2016052017424796 4, and the Opening Project of Key Laboratory of Shaanxi Province for Craniofacial Precision Medicine Research, College of Stomatology, $X_{i}$ 'an Jiaotong University, Grant No. 2016LHM-KFKT010 and 2018LHM-KFKT007. In 
addition, this study was also supported by the Instrumental Analysis Center of Shenzhen University (Lihu Campus) for providing research instruments. Here, we also would like to acknowledge and appreciate Dr. Jieli Wei for a kind gift, LC3-GFP vector, and Dr. Haoxing Zhang for providing the TAF1L-pLV3-IRES-puro vector.

\section{Financial support}

Science and Technology Program, the Science and Technology Innovation Committee of Shenzhen, Grant No. JCYJ20160520174247964; Opening Project of Key Laboratory of Shaanxi Province for Craniofacial Precision Medicine Research, College of Stomatology, $X_{i}$ 'an Jiaotong University, Grant No. 2016LHM-KFKT010 and 2018LHM-KFKT007.

\section{Competing Interests}

The authors have declared that no competing interest exists.

\section{References}

1. Petersen PE. Oral cancer prevention and control--the approach of the World Health Organization. Oral Oncol. 2009;45(4-5):454-460.

2. Leemans CR, Braakhuis BJ, Brakenhoff RH. The molecular biology of head and neck cancer. Nat Rev Cancer. 2011;11(1):9-22.

3. Chi AC, Day TA, Neville BW. Oral cavity and oropharyngeal squamous cell carcinoma--an update. CA Cancer J Clin. 2015;65(5):401-421.

4. Joshi P, Dutta S, Chaturvedi P, Nair S. Head and neck cancers in developing countries. Rambam Maimonides Med J. 2014;5(2):e0009 (20 pages)

5. Bray F, Ferlay J, Soerjomataram I, Siegel RL, Torre LA, Jemal A. Global cancer statistics 2018: GLOBOCAN estimates of incidence and mortality worldwide for 36 cancers in 185 countries. CA Cancer J Clin. 2018;68(6):394-424.

6. Wassarman DA, Sauer F. TAF(II)250: a transcription toolbox. J Cell Sci. 2001;114(16):2895-2902.

7. Lee DH, Gershenzon N, Gupta M, Ioshikhes IP, Reinberg D, Lewis BA. Functional characterization of core promoter elements: the downstream core element is recognized by TAF1. Mol Cell Biol. 2005;25(24):11192-11192.

8. Juven-Gershon T, Kadonaga JT. Regulation of gene expression via the core promoter and the basal transcriptional machinery. Dev Biol. 2010;339(2):225-229.

9. Tavassoli P, Wafa LA, Cheng H, et al. TAF1 Differentially Enhances Androgen Receptor Transcriptional Activity via Its N-Terminal Kinase and Ubiquitin-Activating and -Conjugating Domains. Mol Endocrinol. 2010;24(4):696-708.

10. Filippakopoulos P, Picaud S, Mangos M, et al. Histone Recognition and Large-Scale Structural Analysis of the Human Bromodomain Family. Cell. 2012;149(1):214-231.

11. Kimura J, Nguyen ST, Liu H, Taira N, Miki Y, Yoshida K. A functional genome-wide RNAi screen identifies TAF1 as a regulator for apoptosis in response to genotoxic stress. Nucleic Acids Research. 2008;36(16):5250-5259.

12. Zhang $\mathrm{Q}$, Zhang J, Jin $\mathrm{H}$, Sheng $\mathrm{S}$. Whole transcriptome sequencing identifies tumor-specific mutations in human oral squamous cell carcinoma. BMC Med Genomics. 2013;6:28 (7 pages).

13. Zhong S, Yan H, Chen Z, et al. Overexpression of TAF1L Promotes Cell Proliferation, Migration and Invasion in Esophageal Squamous Cell Carcinoma. J Cancer. 2019;10(4):979-989.

14. Asiedu MK, Thomas CF, Jr., Dong J, et al. Pathways Impacted by Genomic Alterations in Pulmonary Carcinoid Tumors. Clin Cancer Res. 2018;24(7):1691-1704.

15. Nakagaki T, Tamura M, Kobashi K, et al. Profiling cancer-related gene mutations in oral squamous cell carcinoma from Japanese patients by targeted amplicon sequencing. Oncotarget. 2017;8(35):59113-59122.

16. Oh HR, An $\mathrm{CH}$, Yoo NJ, Lee SH. Frameshift Mutations in the Mononucleotide Repeats of TAF1 and TAF1L Genes in Gastric and
Colorectal Cancers with Regional Heterogeneity. Pathol Oncol Res. 2017;23(1):125-130.

17. Necchi A, Lo Vullo S, Mariani L, et al. An open-label, single-arm, phase 2 study of the Aurora kinase A inhibitor alisertib in patients with advanced urothelial cancer. Invest New Drugs. 2016;34(2):236-242.

18. Singh R, Letai A, Sarosiek K. Regulation of apoptosis in health and disease: the balancing act of BCL-2 family proteins. Nat Rev Mol Cell Biol. 2019;20(3):175-193.

19. Doherty J, Baehrecke EH. Life, death and autophagy. Nat Cell Biol. 2018;20(10):1110-1117.

20. Kimura J, Nguyen ST, Liu H, Taira N, Miki Y, Yoshida K. A functional genome-wide RNAi screen identifies TAF1 as a regulator for apoptosis in response to genotoxic stress. Nucleic Acids Res. 2008;36(16):5250-5259.

21. Saha S, Panigrahi DP, Patil S, Bhutia SK. Autophagy in health and disease: A comprehensive review. Biomed Pharmacother. 2018;104:485-495.

22. Singh SS, Vats S, Chia AY, et al. Dual role of autophagy in hallmarks of cancer. Oncogene. 2018;37(9):1142-1158

23. Eisenberg-Lerner A, Kimchi A. The paradox of autophagy and its implication in cancer etiology and therapy. Apoptosis. 2009;14(4):376-391.

24. Langer R, Neppl C, Keller MD, Schmid RA, Tschan MP, Berezowska S. Expression Analysis of Autophagy Related Markers LC3B, p62 and HMGB1 Indicate an Autophagy-Independent Negative Prognostic Impact of High p62 Expression in Pulmonary Squamous Cell Carcinomas. Cancers (Basel). 2018;10(9) (14 pages).

25. Chen $\mathrm{CH}$, Hsieh TH, Lin YC, Liu YR, Liou JP, Yen Y. Targeting Autophagy by MPT0L145, a Highly Potent PIK3C3 Inhibitor, Provides Synergistic Interaction to Targeted or Chemotherapeutic Agents in Cancer Cells. Cancers (Basel). 2019;11(9) (14 pages).

26. Kasprowska-Liskiewicz D. The cell on the edge of life and death: Crosstalk between autophagy and apoptosis. Postepy Hig Med Dosw (Online). 2017;71(0):825-841.

27. Cooper KF. Till Death Do Us Part: The Marriage of Autophagy and Apoptosis. Oxid Med Cell Longev. 2018;2018:4701275 (13 pages).

28. Goodall ML, Fitzwalter BE, Zahedi S, et al. The Autophagy Machinery Controls Cell Death Switching between Apoptosis and Necroptosis. Dev Cell. 2016;37(4):337-349.

29. Chen J, Zhang L, Zhou H, et al. Inhibition of autophagy promotes cisplatin-induced apoptotic cell death through Atg5 and Beclin 1 in A549 human lung cancer cells. Mol Med Rep. 2018;17(5):6859-6865.

30. Qiu Y, Li C, Wang Q, Zeng X, Ji P. Tanshinone IIA induces cell death via Beclin-1-dependent autophagy in oral squamous cell carcinoma SCC-9 cell line. Cancer Med. 2018;7(2):397-407.

31. Hsieh MJ, Lin CW, Chen MK, et al. Inhibition of cathepsin S confers sensitivity to methyl protodioscin in oral cancer cells via activation of p38 MAPK/JNK signaling pathways. Sci Rep. 2017;7:45039.

32. Irimie AI, Braicu C, Pileczki V, et al. Knocking down of p53 triggers apoptosis and autophagy, concomitantly with inhibition of migration on SSC-4 oral squamous carcinoma cells. Mol Cell Biochem. 2016;419(1-2):75-82

33. Ouyang L, Shi Z, Zhao S, et al. Programmed cell death pathways in cancer: a review of apoptosis, autophagy and programmed necrosis. Cell Prolif. 2012;45(6):487-498

34. Naik PP, Mukhopadhyay S, Panda PK, et al. Autophagy regulates cisplatin-induced stemness and chemoresistance via the upregulation of CD44, ABCB1 and ADAM17 in oral squamous cell carcinoma. Cell Prolif. 2018;51(1) (14 pages)

35. Shimomura $\mathrm{H}$, Sasahira $\mathrm{T}$, Nakashima $\mathrm{C}$, Shimomura-Kurihara M, Kirita T. Downregulation of DHRS9 is associated with poor prognosis in oral squamous cell carcinoma. Pathology. 2018;50(6):642-647.

36. Fedchenko N, Reifenrath J. Different approaches for interpretation and reporting of immunohistochemistry analysis results in the bone tissue - a review. Diagn Pathol. 2014;9:221 (12 pages).

37. Sotthibundhu A, McDonagh K, von Kriegsheim A, et al. Rapamycin regulates autophagy and cell adhesion in induced pluripotent stem cells. Stem Cell Res Ther. 2016;7(1):166 (16 pages).

38. Liu S, Xu X, Zeng X, Li L, Chen Q, Li J. Tumor-targeting bacterial therapy: A potential treatment for oral cancer (Review). Oncol Lett. 2014;8(6):2359-2366

39. Argiris A, Karamouzis MV, Raben D, Ferris RL. Head and neck cancer. Lancet. 2008;371(9625):1695-1709.

40. Stransky N, Egloff AM, Tward AD, et al. The mutational landscape of head and neck squamous cell carcinoma. Science. 2011;333(6046):1157-1160

41. Li X, Liang M, Jiang J, et al. Combined inhibition of autophagy and Nrf2 signaling augments bortezomib-induced apoptosis by increasing ROS production and ER stress in pancreatic cancer cells. Int J Biol Sci. 2018;14(10):1291-1305. 
42. Zheng L, Zhu K, Jiao $\mathrm{H}$, et al. PTHrP expression in human MDA-MB-231 breast cancer cells is critical for tumor growth and survival and osteoblast inhibition. Int J Biol Sci. 2013;9(8):830-841.

43. Wu YH, Wu WS, Lin LC, et al. Bortezomib enhances radiosensitivity in oral cancer through inducing autophagy-mediated TRAF6 oncoprotein degradation. J Exp Clin Cancer Res. 2018;37(1):91(14 pages).

44. Maheswari U, Ghosh K, Sadras SR. Licarin A induces cell death by activation of autophagy and apoptosis in non-small cell lung cancer cells. Apoptosis. 2018;23(3-4):210-225.

45. Sophia J, Kowshik J, Dwivedi A, et al. Nimbolide, a neem limonoid inhibits cytoprotective autophagy to activate apoptosis via modulation of the PI3K/Akt/GSK-3beta signalling pathway in oral cancer. Cell Death Dis. 2018;9(11):1087 (18 pages).

46. Zhu B, Li S, Yu L, et al. Inhibition of Autophagy with Chloroquine Enhanced Sinoporphyrin Sodium Mediated Photodynamic Therapy-induced Apoptosis in Human Colorectal Cancer Cells. Int J Biol Sci. 2019;15(1):12-23. 